\title{
Application of substrate utilization patterns and terminal restriction fragment length polymorphism analysis to characterize the oral bacterial community of healthy subjects and patients with periodontitis
}

\author{
YI-JIAN DING ${ }^{1}$, CHAO-RONG GE ${ }^{2}$ and HUAI-YING YAO ${ }^{3}$ \\ ${ }^{1}$ The Stomatology Medical Center and ${ }^{2}$ Department of Clinical Laboratory, The First Affiliated Hospital, \\ School of Medicine, Zhejiang University, Hangzhou, Zhejiang 310003; ${ }^{3}$ Institute of Urban Environment, \\ Chinese Academy of Sciences, Xiamen, Fujian 361021, P.R. China
}

Received June 12, 2014; Accepted February 24, 2015

DOI: $10.3892 /$ etm.2015.2347

\begin{abstract}
Understanding the association between the bacterial community and oral health status is essential for the diagnosis and therapy of periodontal diseases. The aim of the present study was to apply three methods [conventional culture, substrate utilization using the MicroResp ${ }^{\text {TM }}$ system and terminal restriction fragment length polymorphism (T-RFLP)] to investigate the oral bacterial community in saliva from 20 healthy subjects and 20 patients with periodontitis. The three methods all revealed that there was a systematic change in the microbial ecological characteristics associated with oral health status. Compared with the control group, the oral bacterial flora in the patients with chronic periodontitis had a greater culturable population and altered preferred carbon source and TRFLP patterns. TRFLP analysis was found to give more information and exhibit a higher sensitivity than the substrate utilization and conventional culture methods. In conclusion, TRFLP analysis is a potentially rapid method to assess the composition of the oral microbial community and for the diagnosis of chronic periodontitis.
\end{abstract}

\section{Introduction}

Periodontitis comprises a group of chronic inflammatory diseases affecting the periodontium that can result in the loosening and subsequent loss of teeth. Periodontitis is caused by microorganisms that adhere to and grow on the surfaces of the teeth, along with an overly aggressive immune

Correspondence to: Professor Huai-Ying Yao, Institute of Urban Environment, Chinese Academy of Sciences, 1799 Jimei Road, Xiamen, Fujian 361021, P.R. China

E-mail: huaiyingyao@163.com

Key words: bacterial community, periodontitis, substrate utilization, terminal restriction fragment length polymorphism response against these microorganisms (1). Consequently, an understanding of the bacterial flora in the human oral cavity is essential for the diagnosis, prevention and therapy of periodontal diseases; however, since the majority of oral bacteria can not grow under artificial conditions $(2,3)$, a number of community-based microbiological methods are emerging as more effective tools to study microbial ecology in the human oral cavity.

Substrate utilization patterns, assessed using the MicroResp ${ }^{\mathrm{TM}}$ method (4), are a means of investigating the physiological diversity of microorganisms. The MicroResp system is based on measuring the substrate-induced respiration (SIR) of a range of different substrates to generate patterns of potential sole carbon source utilization. Since differences in utilization patterns are interpreted as differences in the major active members of the microbial community, this method has been widely used to examine communities from different environments $(4,5)$. Terminal restriction fragment length polymorphism (TRFLP) is a molecular approach that can be successfully used for the rapid assessment and comparison of complex bacterial communities $(6,7)$. The application of TRFLP has led to the qualitative and quantitative assessment of a significantly larger range of microbial communities than the range that could previously be evaluated using traditional culturing techniques (8).

In the study of the oral bacterial community, saliva is considered to be the most suitable sample, as it is composed of a variety of bacteria from different oral sites (9). Although TRFLP analysis has been used for evaluating the oral bacterial community in a few studies $(7,9)$, the TRFLP method has not been compared with other microbial ecology techniques. The aim of the present study, therefore, was to measure colony-forming units (CFUs) in the unstimulated saliva samples of patients with chronic periodontitis and healthy subjects. The MicroResp and TRFLP methods were additionally used to provide further understanding of the microbial ecology of these saliva samples and to evaluate the hypothesis that the oral community structure would be correlated with oral health status. 


\section{Materials and methods}

Sample collection. Saliva samples were collected in sterile containers from 20 patients with chronic periodontitis (10 males and 10 females; mean age \pm standard deviation, $46.3 \pm 10.8$ years) who had visited the First Affiliated Hospital (Hangzhou, China) and from 20 periodontally healthy subjects (10 males and 10 females; mean age \pm standard deviation, $43.3 \pm 12.5$ years). All subjects who participated in this study understood the nature of the research and exhibited no serious illness. All subjects provided written informed consent. They had not used any antibiotics in the last three months before collection. Each sample contained 5-ml aliquots of saliva.

Plate counts of culturable bacteria. Numbers of bacterial CFUs were estimated by the dilution plate method. The saliva samples were serially diluted with physiological salt solution and suspensions $(0.1 \mathrm{ml})$ spread in six replicates onto the blood agar plates (bioMérieux, Lyon, France). The plates were incubated at $35^{\circ} \mathrm{C}$ and colonies counted after $24 \mathrm{~h}$.

Substrate utilization pattern. The MicroResp system (4) was used to measure the SIR pattern. Briefly, the system utilizes a carbon dioxide detection microplate attached to a $1.2-\mathrm{ml}$ deepwell plate containing the saliva sample and a range of carbon sources. The two plates are connected with a rubber gasket, which forms a seal when the plates are clamped together.

The saliva $(100 \mu \mathrm{l})$ was placed in the deepwell plate and all measurements were performed in triplicate. The MicroResp system was incubated at $37^{\circ} \mathrm{C}$ for $6 \mathrm{~h}$. Basal respiration was measured in wells containing water $(100 \mu \mathrm{l})$ only. SIR was measured by adding one of 15 different carbon sources, which were administered in aliquots of $100 \mu$ l, to generate a final concentration of $20 \mathrm{gl}^{-1}$. The carbon sources used were alanine, galactose, glucosamine, arabinose, glucose, oxalic acid, arginine, protocatechuic acid, citric acid, ketoglutaric acid, malic acid, L-cysteine $\mathrm{HCl}$, lysine, erythritol and xylitol (all from Sigma-Aldrich Co., Ltd., Gillingham, UK).

TRFLP analysis. DNA was extracted using the DNeasy ${ }^{\circledR}$ kit from Qiagen (Hilden, Germany), as per the manufacturer's instructions. For each sample, internal regions of 16S rRNA genes were amplified using the universal forward primer, $63 \mathrm{~F}$, labeled with caboxyfluorescein and the universal reverse primer, 1087R (Sangon Biotech Co., Ltd, Shanghai, China) (10). The labeled polymerase chain reaction amplicons were checked by agarose gel electrophoresis and purified using an UltraClean ${ }^{\circledR}$ DNA purification kit (Mo Bio Laboratories, Inc., Carlsbad, CA, USA). Approximately $100 \mathrm{ng}$ purified DNA products were digested using HhaI (Sangon Biotech Co., Ltd) $(11,12)$. Following digestion, a $2-\mu 1$ portion of each sample was mixed with $0.3 \mu 1 \mathrm{LIZ}^{\circledR}$-labeled internal size standard (Applied Biosystems, Warrington, UK) and $12 \mu \mathrm{l}$ formamide. The analysis of fragment size was performed using an $\mathrm{ABI}$ PRISM $^{\circledR}$ 3030xl genetic analyzer (Applied Biosystems). The fragment analysis of the TRFLP data was conducted between 35 and $1,200 \mathrm{bp}$. All terminal restriction fragments (TRFs) with a fluorescence of $<50$ units were discarded and the relative abundance of the TRFs were used. All peaks with heights
Table I. Loading scores of the most influential individual carbon sources on the first principal component.

\begin{tabular}{llc}
\hline Substrate & Substrate class & Loading score \\
\hline Arabinose & Carbohydrates & -0.433 \\
Glucose & Carbohydrates & -0.376 \\
Galactose & Carbohydrates & -0.312 \\
Citric acid & Carboxylic acids & 0.348 \\
Malic acid & Carboxylic acids & 0.413 \\
Xylitol & Sugar alcohols & 0.517 \\
Erythritol & Sugar alcohols & 0.621 \\
\hline
\end{tabular}

that were $<2 \%$ of the total peak height were excluded from further analyses to avoid potential artefacts.

Statistical analysis. Means and least significant differences at the 5\% level were calculated using a one-way analysis of variance. The SIR and TRFLP data were also analyzed using principal component analysis. The proportional color changes of individual carbon sources in the MicroResp data set and the relative abundance of the individual TRFs in the TRFLP data set were calculated and used for principal component analysis, subsequent to the generation of a correction matrix to transform the data to unit variance. The correlation coefficients were made using simple linear regression. All data analyses were performed using SPSS 16.0 (SPSS, Inc., Chicago, IL, USA). $\mathrm{P}<0.05$ was considered to indicate a statistically significant difference.

\section{Results}

Colony-forming units and substrate utilization patterns. The number of CFUs in the healthy subjects ranged from $2.0 \times 10^{7}$ to $3.0 \times 10^{8} \mathrm{ml}^{-1}$ (mean, $1.1 \times 10^{8} \mathrm{ml}^{-1}$ ) saliva. Larger aerobic bacterial populations were found in the patients with chronic periodontitis compared with the control group, and the average CFU count in the patient group was nearly three-fold higher $(\mathrm{P}<0.001)$ than that in the control group. There was no significant effect of age on the culturable bacteria. The bacterial populations in the saliva were independent on the gender of subjects, and no significant difference was found between the female and male subjects.

The SIR rates for all the carbon sources were above the basal respiration rate (water only). The highest SIR rate was found with glucose and arabinose, and the SIR rates were 11and 14-fold greater than the basal respiration rate, respectively. The addition of amino acids, such as alanine and arginine, had the smallest effect and only increased the SIR rate $\sim 1.5$-fold. Principal component analysis (Fig. 1) using all 15 carbon sources revealed a separation of the samples. The first principal component $(\mathrm{PC} 1)$ of the MicroResp data accounted for $34 \%$ of the variance, and the second (PC2) accounted for $21 \%$ of the variation. The PC1 scores of the patient group were significantly lower than those of the control group (Fig. 1). The oral microbial communities from the patients with chronic periodontitis and the healthy subjects differed in their preferred carbon sources (Table I; Fig. 1). Correlation 
Table II. Correlation coefficients (r) among principal components and the bacterial populations and age of the subjects.

\begin{tabular}{lcccr}
\hline & \multicolumn{2}{c}{ Substrate utilization pattern } & & \multicolumn{2}{c}{ Bacterial TRFLP } \\
\cline { 2 - 3 } \cline { 5 - 5 } Parameter & PC1 & PC2 & PC1 & PC2 \\
\hline Colony forming units & 0.288 & 0.149 & $-0.506^{\mathrm{a}}$ & 0.023 \\
Age of the subjects & 0.154 & 0.085 & 0.176 & $0.368^{\mathrm{a}}$ \\
\hline
\end{tabular}

${ }^{a}$ At 5\% significance level. PC1, first principal component; PC2, second principal component; TRFLP, terminal restriction fragment length polymorphism.

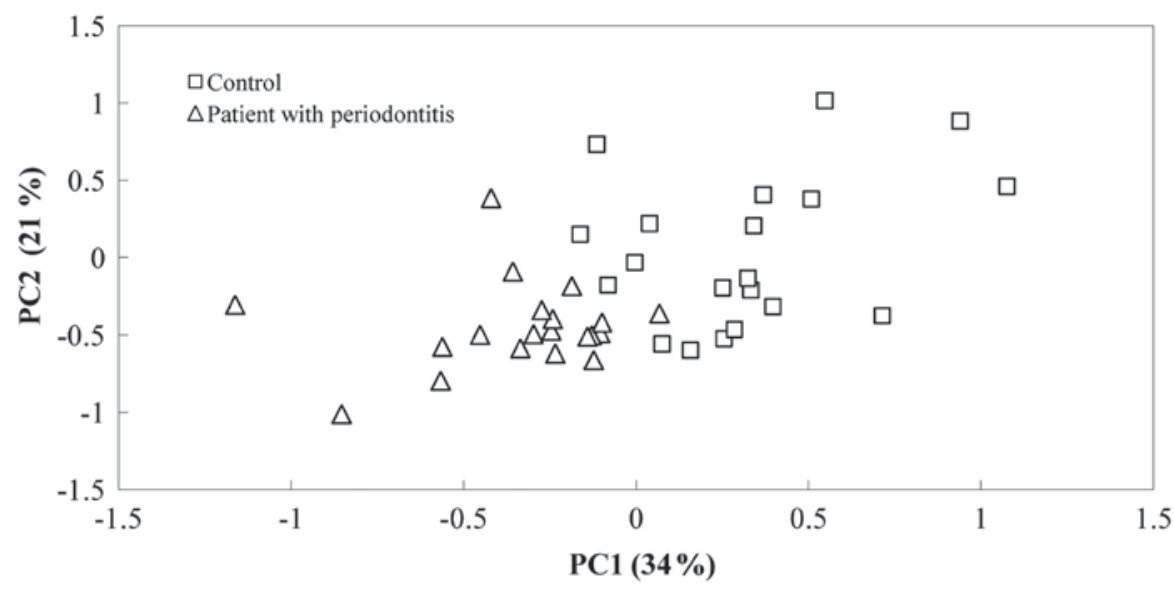

Figure 1. Plot of ordination of PC1 against PC2 generated by principal component analysis of the MicroResp ${ }^{\mathrm{TM}}$ tests. PC1, first principal component; PC2, second principal component.

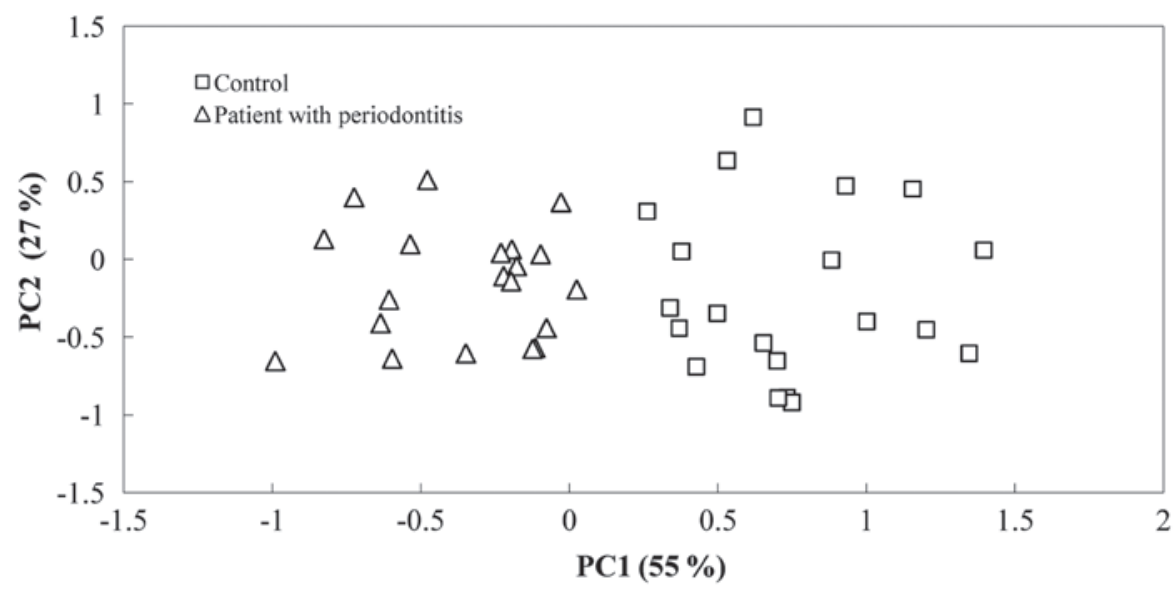

Figure 2. Plot of ordination of PC1 against PC2 generated by principal component analysis of the terminal restriction fragment length polymorphism data. PC1, first principal component; PC2, second principal component.

analysis of the loadings of the most influential individual carbon sources on the PC1 indicated that arabinose, glucose and galactose were preferred by the patient group, whereas erythritol, xylitol, malic acid and citric acid were preferred by the control group. It was found, however, that the principal components (PC1 and PC2) were not correlated with the bacterial populations or age of the subjects (Table II).

Terminal restriction fragment length polymorphism analysis. Each of the saliva samples showed 15-29 TRFs following diges- tion with $H$ haI. A total of 38 different TRFs were detected. Overall, $>90 \%$ of the TRFs were $<600$ bp. The 542 -bp TRF was the most dominant in the TRFLP patterns of all the samples. Principal component analysis of the TRFLP data was used to reveal shifts in the bacterial communities (Fig. 2). The PC1 of the TRFLP data accounted for 55\% of the variance and discriminated the patient group from the control group, indicating that the two groups had different microbial communities (Fig. 2). A significant negative association was found between the PC1 scores and CFUs (Table II). The PC2 accounted for 
Table III. Loading scores of the most influential individual TRFs on the first principal component.

\begin{tabular}{lc}
\hline TRF (bp) & Loading score \\
\hline 68 & -0.473 \\
275 & -0.386 \\
330 & -0.352 \\
436 & -0.311 \\
424 & 0.334 \\
192 & 0.375 \\
45 & 0.448 \\
\hline
\end{tabular}

TRF, terminal restriction fragment; bp, base pairs.

$27 \%$ of the variation and there was a significant positive correlation between the PC2 scores and age of the subjects (Table II). Correlation analysis of the loading scores of the most influential TRFs on the PC1 indicated that the TRFs of 68, 275, 330 and $436 \mathrm{bp}$ were enriched in the patient group, whereas the TRFs of 45, 192 and 424 bp showed increases in relative abundance in the control group (Fig. 2; Table III).

\section{Discussion}

There is now considerable evidence documenting a close association between bacterial community structure and oral health status (7,13-15). The bacterial composition in saliva is more similar to that of the soft tissues than that of the supraand subgingival plaque and can reflect the periodontal health condition in the oral cavity (16). As expected, significantly larger aerobic bacterial populations were observed in the patients with chronic periodontitis in the present study. The function and composition of the bacterial community in saliva is highly correlated with periodontal health.

The substrate utilization method is widely used due to its simplicity and the fact that it yields considerable information about an important functional attribute of microbial communities (4). Since the ability to utilize a range of carbon substrates is fundamental to the ecological functions of microbes in different environments, the difference in the substrate utilization pattern can reflect the difference in the microbial community structure. In the present study, a systematic change in the substrate utilization pattern was associated with oral health status. Oral microbial communities from the patients with chronic periodontitis preferred carbohydrates while those from the control group preferred sugar alcohols and carboxylic acids (Table I; Fig. 1). The results may suggest that the shift in dominant microbial flora in the saliva is correlated with periodontal disease, and that oral pathogenic bacteria may use simple sugars as the preferred energy sources.

The TRFLP technique is commonly used for the evaluation of microbial community composition and has been widely used $(10,17,18)$. The TRFLP patterns allow the rapid comparison of the community composition among patients with periodontitis, and can show host-specific relatively stable oral bacterial flora (9). The present results indicated that the TRFLP patterns derived from patients with periodontitis were significantly different from the patterns of periodontally healthy subjects. The data confirm findings from previous studies, which reported that the saliva from patients with periodontitis contains a special bacterial diversity $(9,19)$. Notably, the present TRFLP results also suggested that the age of the subjects had a significant effect on the oral bacterial flora.

The PC1 of the TRFLP data was significantly correlated with the number of CFUs. This finding may suggest that a change in oral microbial biomass is accompanied by a change in oral microbial community composition, and that certain dominant species determine the size of the microbial community. The 542-bp TRF was found to be the most dominant in the saliva of the healthy subjects and the patients with periodontitis. Compared with the $16 \mathrm{~S}$ rDNA clone library analysis of human saliva (20), the TRF was predominantly derived from the members of the genus Streptococcus. The analysis of traditional isolation and identification demonstrated that Streptococcus was the main genus.

The three methods of conventional culture, substrate utilization pattern and TRFLP analysis were simultaneously applied to assess the size, function and composition of the oral microbial community of healthy subjects and patients with periodontitis. The methods all revealed that there was a systematic change in the microbial ecological characteristics associated with oral health status; however, the results obtained using the respective methods were not in perfect agreement. Bacterial counts were highly correlated with the TRFLP pattern but not with the substrate utilization profile. It appears that the substrate utilization pattern provides information about differences in community functional diversity but they are not always clearly associated with the size of the microbial community (5). Due to the high concentrations of the carbon sources in the MicroResp system, the microbial species that are able to use these carbon sources will grow and reproduce quickly, and the initial microbial biomass may not be the major factor affecting the substrate utilization pattern (21). In the present study the TRFLP method showed more effective discrimination of the samples than the substrate utilization pattern. Furthermore, the TRFLP analysis was able to give more information and exhibited a higher sensitivity than the substrate utilization. The age of the subjects was closely correlated with the TRFLP pattern, but there was no significant effect of age on the substrate utilization pattern (Table II). The present results suggest that TRFLP analysis is useful in studying the composition of the oral microbial community and in the diagnosis of chronic periodontitis, particularly when used in conjunction with other methods.

\section{Acknowledgements}

This study was financially supported by grants from the National Science Natural Foundation of China (no. 81101283) and the Educational Commission of Zhejiang Province, China (no. 20061914).

\section{References}

1. Ehrlich GD, Hu FZ, Shen K, Stoodley P and Post JC: Bacterial plurality as a general mechanism driving persistence in chronic infections. Clin Orthop Relat Res: 20-24, 2005. 
2. Aas JA, Paster BJ, Stokes LN, Olsen I and Dewhirst FE: Defining the normal bacterial flora of the oral cavity. J Clin Microbiol 43: 5721-5732, 2005.

3. Kumar PS, Griffen AL, Moeschberger ML and Leys EJ: Identification of candidate periodontal pathogens and beneficia species by quantitative $16 \mathrm{~S}$ clonal analysis. J Clin Microbiol 43: 3944-3955, 2005.

4. Campbell CD, Chapman SJ, Cameron CM, Davidson MS and Potts JM: A rapid microtiter plate method to measure carbon dioxide evolved from carbon substrate amendments so as to determine the physiological profiles of soil microbial communities by using whole soil. Appl Environ Microbiol 69: 3593-3599, 2003

5. Yao H, He Z, Wilson MJ and Campbell CD: Microbial biomass and community structure in a sequence of soil with increasing fertility and changing land use. Microb Ecol 40: 223-237, 2000.

6. Liu WT, Marsh TL, Cheng H and Forney LJ: Characterization of microbial diversity by determining terminal restriction fragment length polymorphisms of genes encoding 16S rRNA. Appl Environ Microbiol 63: 4516-4522, 1997.

7. Takeshita T, Nakano Y, Kumagai T, Yasui M, Kamio N, Shibata Y, Shiota S and Yamashita Y: The ecological proportion of indigenous bacterial populations in saliva is correlated with oral health status. ISME J 3: 65-78, 2009.

8. Torsvik V and $\emptyset_{\mathrm{v} r e a ̊ s} \mathrm{~L}:$ Microbial diversity and function in soil: from genes to ecosystems. Curr Opin Microbiol 5: 240-245, 2002

9. Sakamoto M, Takeuchi Y, Umeda M, Ishikawa I and Benno Y: Application of terminal RFLP analysis to characterize ora bacterial flora in saliva of healthy subjects and patients with periodontitis. J Med Microbiol 52: 79-89, 2003.

10. Singh BK, Nazaries L, Munro S, Anderson IC and Campbell CD Use of multiplex terminal restriction fragment length polymorphism for rapid and simultaneous analysis of different components of the soil microbial community. Appl Environ Microbiol 72: 7278-7285, 2006.

11. Osborne CA, Rees GN, Bernstein Y and Janssen PH: New threshold and confidence estimates for terminal restriction fragment length polymorphism analysis of complex bacterial communities. Appl Environ Microbiol 72: 1270-1278, 2006.
12. Horz HP, Ten Haaf A, Kessler O, Said Yekta S, Seyfarth I, Hettlich M, Lampert F, Küpper T and Conrads G: T-RFLP-based differences in oral microbial communities as risk factor for development of oral diseases under stress. Environ Microbiol Rep 4: 390-397, 2012.

13. Loesche WJ, Syed SA, Schmidt E and Morrison EC: Bacterial profiles of subgingival plaques in periodontitis. J Periodontol 56: 447-456, 1985

14. Ximénez-Fyvie LA, Haffajee AD and Socransky SS: Microbial composition of supra- and subgingival plaque in subjects with adult periodontitis. J Clin Periodontol 27: 722-732, 2000.

15. Kumar PS, Leys EJ, Bryk JM, Martinez FJ, Moeschberger ML and Griffen AL: Changes in periodontal health status are associated with bacterial community shifts as assessed by quantitative 16S cloning and sequencing. J Clin Microbiol 44: 3665-3673, 2006.

16. Mager DL, Ximenez-Fyvie LA, Haffajee AD and Socransky SS: Distribution of selected bacterial species on intraoral surfaces. J Clin Periodontol 30: 644-654, 2003.

17. Marsh TL, Saxman P, Cole J and Tiedje J: Terminal restriction fragment length polymorphism analysis program, a web-based research tool for microbial community analysis. Appl Environ Microbiol 66: 3616-3620, 2000

18. Saito D, Marsh TL, de Souza Cannavan F, Höfling JF and Gonçalves RB: Assessment of intraradicular bacterial composition by terminal restriction fragment length polymorphism analysis. Oral Microbiol Immunol 24: 369-376, 2009.

19. Hutter G, Schlagenhauf U, Valenza G, Horn M, Burgemeister S, Claus $\mathrm{H}$ and Vogel U: Molecular analysis of bacteria in periodontitis: evaluation of clone libraries, novel phylotypes and putative pathogens. Microbiology 149: 67-75, 2003.

20. Sakamoto M, Umeda M, Ishikawa I and Benno Y: Comparison of the oral bacterial flora in saliva from a healthy subject and two periodontitis patients by sequence analysis of $16 \mathrm{~S}$ rDNA libraries. Microbiol Immunol 44: 643-652, 2000.

21. Bååth E, Díaz-Raviña $M$, Frostegård $S$ and Campbell CD: Effect of metal-rich sludge amendments on the soil microbial community. Appl Environ Microbiol 64: 238-245, 1998. 